\title{
Older Adults and Their Life Experience: What Can We Learn from Them?
}

\author{
Ami Rokach* and David Berman \\ York University, Canada
}

\begin{abstract}
This study contemplates the role which reminiscing by older adults can play in facilitating beneficial outcomes by helping prepare for end of life via creating a cohesive life narrative and generative of personal meaning. When considering these benefits and the wisdom embedded in the life stories of older adults, this study's goals included both: Facilitating reminiscing through open-ended interviews and fostering generational learning by analyzing the life experiences of older adults for life lessons and wisdom therein. We hypothesized that not only would the interview process itself promote reminiscing but also document the life knowledge of the older adults which could then be thematically analyzed and distilled into accessible "pearls of wisdom". The interviews were conducted in Canada with 132 participants who were between 60 to 94-years of age utilizing six questions designed to facilitate further commentary. During the interview process we were able to document a wide array of experiences which we categorized into the themes which were entitled: dealing with personal difficulties/insights on life and adapting, relationships with parents and older adults, and satisfaction from life.
\end{abstract}

\section{Keywords}

Reminisce, Elderly, Older Adults, Qualitative, Narrative, Knowledge, Generational, Meaning in Life, Ageing, End of Life

\section{Introduction}

When I (AR) grew up, I often heard "when you grow up you will know and understand." The communication gap this statement alluded to was thrown into sharp relief when I saw how older adults and younger peoples interacted with one another. Thankfully, I also realized that there is a way of getting to the knowledge that older adults have accumulated over their lifetime and work to pass it along to younger generations, and thus saving them from decades of mistakes, trials, and tribulations. It also later occurred to me that by listening and learning from older adults, we can lessen the feelings of loneliness that many people confront in their later years.

As life draws to a close, reminiscence and life review occurs naturally $[1,2]$. As death looms closer during the second half of a person's life, the interpretation of one's past life takes on an increasingly larger role when bestowing meaning on one's life [3,4]. Whitbourne [5] found that, throughout life one tends to periodically review their past by ranking and evaluating their experiences. These renewed constructions are significantly associated and influenced by external life conditions such as historical, cultural, social, and material circumstances. Further, these constructions are also impacted by internal life conditions, which are represented by both psychological and biological dimensions. Research indicated that psychologically healthy people typically achieve a positive life audit, where they become aware of their failings and negative experiences, but do not evaluate them as predominant [4].

Erikson [2] described the stages of human age-related development, addressing ego-integrity as the acceptance of life as it is, and as a product of a fulfilled life. Life review, even of unfulfilling life, can help in achieving acceptance and possibly fulfilment. Research has also found that acceptance of one's achievements in life can aid in preparing to face death with appreciably decreased fear [6]. While Baum [7] found that when older adults disengage from more active life a review can enhance one's acceptance of the life lived. Related to this, Cross, et al. [8] found that older people judge themselves more kindly than younger people do. Reminiscence is the active or passive recalling of memories from the past and are an important source of identity and self-continuity [9-11]. Reminiscing has been utilized, therapeutically as a strategy for stress reduction $[12,13]$. While Butler [1] described such life review as "an inner experience or mental process of re-

*Corresponding author: Ami Rokach, York University, Toronto, Canada

Accepted: November 28, 2020

Published online: November 30, 2020

Citation: Rokach A, Berman D (2020) Older Adults and Their Life Experience: What Can We Learn from Them?. J Nurs Pract $3(1): 202-211$

Copyright: (C) 2020 Rokach A, et al. This is an open-access article distributed under the terms of the Creative Commons Attribution License, which permits unrestricted use, distribution, and reproduction in any medium, provided the original author and source are credited. 
viewing one's life" [13] conducted a meta-analysis evaluating the efficacy of reminiscence therapy and found people who were offered this therapeutic approach, reported greater increases in happiness and decreases in depressed mood, while showing increased insight and a more optimistic outlook [9].

\section{How Do Older Adults Benefit from Reminisc- ing and Life Review?}

Research has demonstrated that in older adults, life review can enhance general wellbeing $[12,14,15]$. These effects range from increasing self-esteem [16], life satisfaction, and reducing loneliness, depression, dementia, and mental disorders in older adults $[17,18]$. Life review was also found to help improve social contact and foster a sense of belonging [19].

By recounting their past events, their wishes and achievements, older people can transmit their life experience, and the lessons they learned to the younger generations. Intergenerational reminiscence also enhances closeness between generations [20-22]. When the older adults conduct life reviews with younger people, it was shown to decrease negative perceptions about older adults, which can negatively affect those older adults [23]. Positive intergenerational contact can reduce stereotypes that older adults themselves may hold [24]. Life review has been shown to increase self-esteem, one's sense of meaning, and purpose in life among older adults, as well as decreasing depression which a segment of the older population struggles with $[14,25]$.

\section{About this study}

We found that most older adults enjoy talking about their lives and sharing their experiences with others. It should be noted, though, that they were given some freedom in what they choose to talk about, since older adults are not homogeneous, not all of them were prepared to share the same kind of details about their life. As was earlier mentioned, this study aimed at connecting the younger and the older generations, in a manner that would benefit all participants. Scott and DeBrew [26] found that these benefits remained for, both, older adults who were interviewed and by the students [research assistants] who interviewed them. It was noted that, delightfully, the students' ideas about older adults were changed, now being more comfortable talking with older adults. The value of life reflection as a nursing intervention has also been instilled for the student.

\section{Method}

\section{Participants}

Sixty-six men and sixty-six women, aged 60 to 94 ( $\mathrm{M}=$ 77.9) participated in this project. Participants were recruited via the snowball technique, where one participant invites others they know to participate. These contacts came from community centers, public parks or their residences, and sometimes by recommendation by someone they knew. Participants were read the informed consent but were not asked to sign it, due to their great concern of signing anything without a family member being present and wished to preserve their anonymity. The research was approved by the Institutional
Review Board of the university to which the authors belong. Interviewers included a total of four female undergraduate psychology students in their beginning twenties. They were chosen specifically for this study since our goal was to have the older and younger generations meet and spend valuable time in each other's company.

\section{Procedure}

The present research, by asking of the participants several questions [outlined below], was akin to constructing oral histories which were defined:

...as a method for assessing the stories and records that aid in the understanding of previous events in history as well as the feelings surrounding such events. Although oral history research utilizes less structured approaches than other methodologies (e.g., researchers are encouraged to follow cultural norms, practices, and intuition when conducting an interview rather than relying on standardized interview techniques), asking similar questions across participant interviews generates consistency...The flexible style of oral history research offers advantages to participants, including greater openness story sharing and provides participants with greater control in setting the pace of the interview [27].

Interviewing older adults, we did not use structured questionnaires since older adults are a heterogenous group, and each has his or her own life experience, knowledge, and the way to relate it. Instead, research assistants met with older adults who volunteered, for a period of approximately 30 minutes, and asked them four identical questions (along with some biographical questions regarding their age educational level and marital status):

1. What have you done in life that you are glad you did?

2. What have you not done in life that you are glad you did not do, and,

3. What have you achieved in life and how did you manage those achievements?

4. Are there any "pearls of wisdom" you would like to share, for the benefit of the younger generation?

The interviews were recorded, with the participant's permission, and later transcribed. Themes were, then, 'distilled' out of their life review and grouped into categories by the two authors.

\section{Analysis}

The data gathered underwent thematic analysis [28]. "Thematic analysis is a method for identifying, analysing and reporting patterns (themes) within data. It minimally organizes and describes your data set in (rich) detail. However, frequently it goes further than this, and interprets various aspects of the research topic" (p. 79).The recorded interviews were transcribed and then analyzed for embedded 'pearls' which we saw as wise reflections on one's life and which could later be transmitted to younger generations. As suggested by Braun and Clarke, themes were identified if they captured an important issue related to the research question and repre- 
sented some level of patterned response or meaning within the data set were identified. In order to establish interrater reliability, the two authors of the present paper, with the assistance of two research assistants, conferred, reviewed the data and decided what formed the various themes and how to name them. Inter rated reliability for finding 'pearls' which; later formed themes was $95 \%$.

Braun and Clarke [28] observed that the analytic process involves a progression from description, where organization according to patterns in semantic content are summarized and then interpreted, and an attempt to theorize the significance of the patterns and their broader meanings may follow. However, a thematic analysis at the latent level goes beyond the semantic content of the data and examines underlying ideas, and conceptualizations which may be shaping or informing the semantic content of the data.

\section{Results}

\section{Theme \#1: 'Dealing with personal difficulties/in- sights on life and adapting'}

Working with the assumptions that all people face challenges in their lives, we sought to document the related "pearls of wisdom" to these experiences as adaptive strategies. The ability to overcome trials is associated with a range of traits (e.g. determination, conscientiousness) as well as applicable knowledge. The fecundity of this theme allowed us to further sort it into the following subthemes:

a. 'Acquiring knowledge \& learning from experiences' - Captures the importance of learning from experiences and how that information can be effectively utilized for future challenges. Knowledge is seen as having intrinsic value for the individual and the wider community with a focus on learning from others. Examples of the "pearls" that were included are: [Person \#31, Male, 75 years old] "Knowledge is never useless.", [Person \#43, Male, 77] "Smart people learn from their own mistakes, but wise people learn from the mistakes of others.", [Person \#20, Female, 80] "You live and learn. Life experiences sort you out too".

b. 'Determination and hard work in facing adversity' - The participants discussed how they were able to overcome challenges by remaining resolute in the face of adversity. The themes of hard work and working through difficulties were repeatedly mentioned as a universal solution to many problems. Examples of the 'pearls' included: [Person \#1, Male, 84] "Conscientiousness is more of a hardworking attitude more than a talent.", [Person \#11, Female, 75] "All I can say is fight, fight, fight, for everything you want in your life. Just go out there and knock them dead. And let those people know you are going forward no matter what", [Person \#31, Male, 75] "Work hard, have discipline and try not to worry too much about what everybody else is doing".

c. 'Avoiding trouble, being cautious and vigilant' - This theme contained references of not making life more difficult than it needs to be, understanding one's own limitations and being vigilant against temptations. The par- ticipants expressed the importance of caution, reserving judgement, and self-reflection. A sample of some of these contributions were: [Person \#31, Male, 75] "Life is difficult when you make it difficult", [Person \#80, Male, 71] "It's ok to not take a position. I say to myself, I don't know the answer, I don't know who's right, so I back up", [Person \#96, Male, 77] "If you want a peaceful life, stay away from bad things, and try to do the good. Try to be in good society".

d. 'Seeking help, taking advice, accepting what cannot be changed' - It is a common experience to face difficulties and not know the best course of action. Our sample data highlights the importance of seeking help, admitting to what you do not know and the value of expertise. Some of these entries included: [Person \#4, Male, 78] "In moments of crisis seek out wisdom", [Person \#65, Male, 77] "I would advice to talk to the person you feel most comfortable with, to give you some help, or those who are counsellors", [Person \#132, Male, 66] "Be open to different points of view and discuss the issues without becoming personal".

e. 'Loneliness and the importance of relationships' - Loneliness has become a ubiquitous factor of modern life, because of that, it is unsurprising themes related to loneliness and closeness to others appeared in the corpus. The participants offered thoughts on their own experiences and how close relationships can help guard against its expression. Several examples include: [Person \#24, Female, 80] "Everyday that I do not see my children I am lonely as can be. I cry. I miss them a lot. It's strange that when they were younger, they missed and cried for me. Now the tables have turned. How interesting life is", [Person \#66, Male, 79] "My biggest challenge was that I never found a lady to marry. I stayed single and accepted that, so my nieces and nephews, and great nieces and nephew became my children", [Person \#67, Male, 70] "Socializing is very important, I think if you quit communicating with people I think that's a sign you're going downhill".

f. 'Avoiding or controlling vices' - The moral hazards that vices can present people are discussed in the sample data as the participants spoke of attempts to moderate behaviour and look for ways to control unwanted impulses. Most of the contributions focused on avoidance, self-control, having a goal, and the damage that drugs and alcohol can have on a person and society. Some of the entries included: [Person \#25, Male, 72] “Don't become a drunk or drug addict, have discipline and self-control.", Person \#42, Male, 82 - Pearl 332 - "Don't drink too much vodka, it will ruin you and other people around you", [Person \#84, Female, 80+] "I stayed away from the crowds that would badly influence me. If I got in their sights I would just say "no I told you, no nonono".

g. 'Allow yourself to be who you are!' - The importance of having confidence and allowing yourself to be who you are, especially in front of others, is seen as a path towards self-fulfillment. Since it is difficult to obtain a measure of happiness if you are pursuing the goals that society, or family, has laid out instead of your own interests it is 
necessary for a person to establish what they want and the self-confidence to pursue it. The participants in this study offered many insights related to this theme, including: [Person \#4, Male, 78] "Being reflexive, self-aware and thinking about your own thoughts is important", [Person \#27, Female, 72] "Speak your mind more. Do not be afraid! Life's too short to cower and kiss everyone's ass in some hope of gaining something out of it", [Person \#55, Male, 86] "Do what you are convinced you should be doing, day by day and sometimes you win and sometimes you lose".

h. 'Be the best you, and see the best in others' - Striving to be the best version of ourselves often includes the ability to see the best in others. Either in being inspired by others' example or having the compassion and optimism to see the best in other people. Older adults spoke to these themes by encouraging people to be morally upstanding, take responsibility for their actions and love their fellow humans. Some examples of these "pearls" are: [Person \#19, Female, 82] "Nobody is bad all the time, everybody is mostly good, they are just bad sometimes", [Person \#41, Male, 75] "I want young people to remember that life is too short to hate. That person you hate today could be someone you love tomorrow, or maybe someone that you've loved before. It takes less effort to love, and it feels better too. Life is complicated as it is, it doesn't have to be even worse", [Person \#97, Male, 74] "Try to give advice and help those in poverty, there are many who are".

i. 'Finding comfort in faith' - For many people their faith is a source of strength, providing them with guiding principals as well as a stable community. Some examples of faithbased themes included: [Person \#37, Male, 74] "Religion is important, Jesus has helped me many a time when I was struggling", [Person \#55, Male, 86] "We need to sensitize people to creation and the mess we made by exploitation of the resources of the earth", [Person \#124, Female, 66] "My Christian lifestyle kept me on a good path, straight and narrow. Knowing that if I did get in trouble, I had God and prayer that would steer me to the right place".

j. 'Being aware of what the important things in life are' The participants spoke about how contentment was best achieved by paying attention to the things that give meaning to one's life. Contrasted with that, the striving to obtain money and materialistic things were reported as a short-sighted and unfulfilling. Some examples of this theme are: [Person \#105, Male, 68] "Don't let material things, things that are unimportant become your focus", [Person \#105, Male, 68] "If you got everything you wanted in life, life would be boring. If you have a billion dollars it becomes meaningless. If you are only successful in material things, then you have lost".

k. 'I am the captain of my ship' - Older adults in this study contributed their thoughts on people taking responsibility for their actions and how it can facilitate pride in accomplishments, self-reliance, and not being a burden on others. Some of the pearls related to these themes that appeared in the corpus consist of: [Person \#50, Female, 89] "If you don't make it for yourself, nobody is going to make it for you", [Person \#130, Female, 60] "I managed everything, the servants looked after the house work when I would leave for my job in the morning and return in the evening", [Person \#94, Female, 72] "Do not make trouble for your parents and take charge of your own responsibilities".

I. 'Appreciation, optimism, focusing on the good life' - In light of all the challenges people face it is important to remain optimistic and not be pulled down into negative and despairing thoughts. Giving challenges your best effort, being there for others, and working towards a better future were all "pearls" present in the corpus. Several examples of this them are as follows: [Person \#60, Male, 78] "Think about the good things you have, not the troubles, the good things, that's most important", [Person \#72, Female, 72] "I see the glass as half full", [Person \#81, Female, 78] "Try to do what you want and then bring your wheelchair [if you have one]. Don't say l'm in a wheelchair first because you don't know until you try".

m. 'Self-Reliance, resilience' - There were many references to overcoming challenges when a person has no one else to rely on. It is in those times the participants highlighted the importance of conjuring up the internal strength to persever. This subtheme included enduring some psychological pain, but also in having conviction that there is light at the end of the tunnel. Participants in this study offered the following examples: [Person \#63, Female, 77] "I was a single parent back in the 60 's, it was a very difficult time to be a single parent and raise a child, but I did it", [Person \#102, Female, 79] “I'm an independent person and I don't like relying on other people for doing things. I like to make up my own mind of what is going to happen, so I'm happy I got a divorce", [Person \#81, Female, 78] "I've always taken care of myself so I've never ran into the problem where I had to have government's help. Like having someone come in and help get me up, I've always done that myself".

n. 'Healthy living and dealing challenges' - Medical problems can affect people of any age but are of particular concern for older adults. Concerns for the ill, the need for compassion, living a healthy lifestyle and an emphasis on the role psychological strength plays were all present. This theme was unsurprisingly well represented in the interviews with the following as some examples: [Person \#67, Male, 70] "I'm on medication because there were heart problems and I did have open heart surgery a few years ago which I just came through. I also just finished a knee replacement 11 weeks ago, so now I'm recovering from that", [Person \#81, Female78] "I hate to say it, but families are part of the problem. When they don't understand, they are like the rest of the public, they look at you like you are useless. I know a woman in a wheelchair who was waiting for her ride when a lady from her building came by and told her off because her tax money was paying for her transportation", [Person \#108, Female, 85] Eat healthier food and be aware of the food you eat because your health is so dependent on that. Avoid being overweight as it can lead to medical problems". 
o. 'Finding peace and contentment' - Finding peace and contentment included understanding of what a person has control over and what they do not. It also comprised the need to identify what is important and what makes a person fulfilled as the road to happiness. The following are some examples: [Person \#17, Female, 75] “Getting out of an unhappy and unstable marriage left me with no regrets", [Person \#115, Male, 72] "Be a stoic. Divide the world into two, things you can't control and those things you can. You can choose what you want to be, you can choose to be happy", [Person \#117, Male, 67] "Be happy with what you do. If you are miserable at work, you will be miserable at home. If you are miserable at home, your family will be miserable. You have to do what you love doing or move one, change".

p. 'Taking an active part in planning your life' - Planning ahead, being prepared for challenges and meeting expectations is an important part of people's lives. Older adults also stressed the central role making educated financial decisions plays when trying to realize a stable and happy life. The following are examples found in the interviews: [Person \#90, Male, 81] "Study history so you don't make the same mistakes", [Person \#101, Male, 70] "Whenever it was a difficult time I always made sure I had money on the side. And I never tried to bite off more than I could chew. I could have survived for two years with what I had, always make sure you have a backup when something goes wrong", [Person \#129, Female, 70] "Always look out for yourself, always. Think about yourself and always put aside some money for yourself because I think that is very very important because anything can happen".

q. 'Adapting to what is' - The concept of ever-present change appears in this subtheme as the participants spoke to the necessity of adapting to a changing world and frustrations of not being able (or the desire) to keep up. Examples include: [Person \#83, Female, 83] "If you're going to be unhappy because of expectations, you're going to be miserable your whole life. I would have liked to have a had a happy marriage but it didn't work out that way, so I adapted", [Person \#109, Female, 82] "Things change and you just have to keep going with the changes", [Person \#61, Male 73] "The world is changing very fast and you have to cope with it".

r. 'Be truthful' - The importance of keeping one's word was discussed in the interviews as the consequences for deceit were depicted as long-lasting and not easily resolved. Our study found the following three examples of this theme: [Person \#84, Female, 80+] "If you make a promise to a friend and you don't keep it for some reason, don't expect them to just take it. Make it clear from the beginning you are not going to do that thing, tell them to find someone else", [Person \#84, Female, 80+] "Always keep your word, if you can't let them know, if they can't accept it, well, then you just have to drop them", [Person \#97, Male, 74] "You should be honest. Don't lie to anyone".

\section{Theme \#2: 'Relationships with Parents and Older adults'}

The participants understood that in order to facilitate intergenerational learning, a relationship between children, parents, and older adults was highly beneficial. The advice and commentary were again subdivided into several subthemes.

a. Communicating, learning from their experience - A premium was placed on listening and engagement as parents and older adults were depicted as possessing experience of considerable value. This advice was characterized as a path to an easier life and a solution to the challenges of life. [Person \#2, Male, 81] - "Well one pearl of wisdom is listen to your parents. Because they are usually smarter than you are. You think you are smarter than them, but most of the time, you're dumber than them and you find out afterwards unfortunately that they were right.", [Person \#63, Female, 77] - "You have to have communication and respect with your parents.", [Person \#130, Female, 60] - "Listen to your parents. We always think that what our parents are saying is wrong, we don't like it when they tell us things. That is how I felt too. But now I realize that when we listen to our parents, like when tell us to work hard, be educated, it is for our own good".

b. Respecting older adults - Pleas to respect and care for older adults were documented with concerns about health and isolation being at the forefront. [Person \#61, Male, 73] - "Respect elderly and care about them. The younger generation is losing this with all this technology. When you get together, don't look at your cell phone. Put everything away, talk to each other.", [Person \#86, Female, 84] - "When older people suffer from mental issues, they are like babies again, so we should pity and respect them." [Person \#113, Male, 72] - "A lot of young people don't respect older people".

c. Helping to Care for Parents - Some of the interviews touched on caring for older adults as they begin to lose the capacity to care for themselves. This caring and concern were depicted as a way to repay them for all they have done for their children and it just being the virtuous thing to do. There was also a thread of regret for those who had not treated own parents as well as they thought they should: [Person \#17, Female, 75] - "I could have been kinder to my parents, I could have treated them better." [Person \#67, Male, 70] - "It is important to look after your parents when they get older. I felt the responsibility of a children to look after their parents. I mean, after all, look what their parents have done for you, sacrificed for you. I didn't want to see her go into of those long-term care facilities. It was loyalty and a sense of responsibility, to make sure she was looked after properly." [Person \#130, Female, 60] - "I got a lot of support from my family. In my family, I obeyed all my duties, when I was with my parents I did all the duties a daughter does. At my in-laws I did all my duties, I did everything with honesty".

d. Express Your Love to the Family - Older adults encouraged younger people to initiate communication with older family members and to avoid being selfish with time. [Person \#93, Female, 87] - "Never be too busy to pick up 
the phone to say a mother "grandmother, I love you". I have two grandchildren who never call me because they are too busy. I was busy all my life but I always made time. I would make less time for myself to make time for those I loved." [Person \#93, Female, 87] - "The younger generation must learn, you might have everything but that will never replace the love you share with your family. That is what God made family for, to love one another".

\section{Theme \#3: 'Satisfaction from life'}

In the interviews there was an association made between having satisfaction from life and having a life of meaning. By sharing what gave their own lives meaning they gave examples of what might also be meaningful to others in hopes it would help younger generations navigate their lives in productive and self-fulfilling ways. Because of the robust response for this theme we further divided it into the following subthemes:

a. 'Importance of Friendship' - Friendships have always been an effective guard against loneliness while providing a sense of community for the young and old alike. Older adults in this study spoke about how friends can also have a central role in providing intimacy and source of strength. A few examples of this subtheme include: [Person \#66, Male, 79] "To form close relationships be open, accepting and not being judgemental, that's the foundation" , [Person \#67, Male, 70] "I have close friends, we get together for dinner or something like that, or go out. I have one friend I talk to every second day, we usually get together on the weekends for dinner or lunch and two other friends, we do the same thing, it is good to go out socialize", [Person \#105, Male, 68] "If you enjoy life, keep friendships, that is success".

b. 'Pride in Accomplishments, Personal Growth' - Being proud of life accomplishments is perhaps more of a concern for older adults, but the youth can still benefit from being proud of their progress and use that as inspiration to tackle goals in the future. While working towards accomplishing goals is consistent with healthy life strategies, always striving for things which you do not have, can undermine accomplishments and lead to lingering frustration. Some of the accomplishments the participants offered were: [Person \#4, Male, 78] "I am proud of becoming a runner at the age of 37 or 38, ran a few marathons", [Person \#18, Female, 92] "Glad I didn't continue smoking", [Person \#2, Male, 83]- "I'm happy with what I got, I'm happy with what I did. What I should have done is a different story. I'm very satisfied with what I did".

c. 'Acting appropriately, morally and with humility' - having a moral compass, whether it is founded in religious teachings or a personal ethical code is a way to avoid regrets and build better communities. In this study it was also associated with the notion of a universal justice where good things happen to good people. Some of the entries are: [Person \#21, Female, 77] "I never acted on anything I feel remorseful for. I Stayed away from the bad stuff", [Person \#37, Male, 74] "Just be a good person and good things will happen to you", [Person \#103, Male, 76] “I didn't drink, smoke or chase women and I think my health has been good because of that".

d. 'Success requires work and perseverance' - In the age of social media where the illusion of "success" can be had in a moment, it is important to stress that stable, realistic and personally meaningful success comes from effort and determination. The ability to shrug off disappointments and stick to a goal were highlighted as important strategies to long term success: [Person \#9, Female, 75] "When things are rough, don't dwell on it, just keep going, things will settle", [Person \#74, Female, 79] "Follow your dreams of what you want to do", [Person \#114, Female, 81] "I'm glad I got a part time job when my kids were old enough, it is a small achievement to a lot of people, but it is an achievement".

e. 'Helping and caring for others' - Helping others in their time of need was a theme well represented in the corpus with the participants stressing how rewarding it can be. The concept of building better communities by caring for one another and the sense that we are all in this together revealed itself. Some of the "pearls" included: [Person \#98, Male, 74] "I found that in life when you are good to people, one day the universe will turn around and they will be good o you", [Person \#99, Female, 76] "Volunteer work was very satisfying. You can meet a lot of interesting people while knowing that you were doing something worthwhile, something helpful for the community, giving you a sense of satisfaction", [Person \#111, Female, 75] "I get happiness from helping others".

f. 'Resilience, being true to yourself' - At times when confronted by challenges it seems easier to compromise what is important for an expedient solution. Older adults here stressed against this and promoted the importance of maintaining faith in one's own self and being an independent agent when your personal values are threatened. [Person \#5, Female, 76] "Be true to yourself. Once you are true to yourself, then you are being true to everyone else", [Person \#9, Female, 75] "Because there is no perfect life, you need to accept stuff that is thrown at you. Deal with it as best as you can", [Person \#36, Female, 77] "I'm glad I didn't sell myself out. I'm glad that I kept my integrity, loyalty and my sanity intact".

g. 'Inviting positivity into my life, appreciating what I have' Avoiding people who may have a negative influence and trying to keep a positive attitude, takes effort. Our participants made the connection between maintaining a good attitude towards life as way to rise above the troubles in life. Some of the recorded themes were: [Person \#9, Female, 75] "They say happiness is not forever, but bad luck doesn't last forever too. Just take every minute and enjoy it", [Person \#11, Female, 75] "Don't be negative. People who feel that their life is terrible and yet they have everything to live for and help and family and money and yet they don't see past whatever they are negative about. That makes me angry.", [Person \#99, Female, 76] "Live each day the best you can, look for the positive and don't 
dwell on the negative. It's too easy to do that. You don't have to be a Pollyanna, but you can look at the bright side as they say. I think if you have a positive attitude and you have a joy of living, that gets you through most things".

h. 'The importance of family and children" - Families can be central to what people consider important in their lives while being a source of strength and an accomplishment in its own right. The participants spoke of the benefits of having children and the community that a family can provide for people: [Person \#29, Female, 75] “I have been a good mother, a faithful wife and I've kept my family together. To me, that is more important than any career a person can have, and more important than the amount of money a person has. You can't buy that as you know", [Person \#34, Male, 71] "My wife respected me, and my kids respected me. That's all that matters in this world", [Person \#66, Male, 79] "My greatest success has been looking after my nuclear family as well as my big family. Brothers, sisters, cousins, mom, dad, uncles that's because I tend to be the godfather of the clan. I never married, so I didn't have any children, I don't have a wife, so the family became my goal".

i. 'The importance of faith' - Faith for many is a guiding light that can bring comfort in difficult times and provide a set of tenets to live by. Older adults in the study commented on how faith provides people with a purpose while also highlighting the importance of being humble. Contributions to this theme include: [Person \#37, Male, 74] "Be true to yourself and follow what Jesus taught, life doesn't have to be too complicated", [Person \#91, Female, 80] "I had faith in myself and God", [Person \#96, Male, 77] "Make higher goals and you will get the blessings of God and people too".

j. 'The importance of one's roots' - Maintaining connections to your culture, customs, and communities can provide a sense of not being alone in the world. A person's roots can also help provide a sense of identity, as the participants offered: [Person \#28, Male, 80] "Love your history and your culture", [Person \#43, Male, 77] "Sticking to my Guyanese roots was important. Too many people forget who they are, but it's important to know who you are. If you have that knowledge, you will never make the mistake of disrespecting yourself and your people. You'll have confidence", [Person \#43, Male, 77] "Our roots were things that nobody could take away, except for ourselves. That's why it is important to know them and cherish them, because when you have very little, those things mean a whole lot".

k. 'Appreciation, living a full life and now!' - Making the most out of life can mean making the most of each and every moment and realizing how precious and fleeting it is. The participants recorded their thoughts on a wide range of interests but were consistent in their urging to seize the day: [Person \#8, Female, 83] "I think success is just having good friends, being able to stand on your own two feet and have a happy home life and happy family", [Person \#35, Female, 78] “Live each day to the fullest. Don't do things if you don't want to do them", [Person \#105, Male, 68] "Live for the moment, enjoy what you have, your family, your surroundings".

I. 'Taking personal responsibility' - Taking personal responsibility for our behaviour is seen as a great way to motivate people to take responsibility while fostering healthy life outcomes. Older adults in this study repeatedly made references to personal finances and the importance of making wise decisions with money in order to build a brighter future. Some examples of how older adults spoke about this theme include: [Person \#6, Male, 78] "Start thinking of finances, putting away a bit for a rainy day, as you are going to be around for a long time", [Person \#47, Male, 81] "Save as much as you can from a young age. Everybody has different circumstances, it depends how much you earn", [Person \#66, Male, 79] "Take responsibility for yourself, share your love and commitment with your family and respect everybody".

m. 'Staying Active' - The health benefits of staying active are of great concern for older adults who may have to face the consequences of an earlier inactive life. The participants spoke of their efforts to stay active and the residual benefits that arise out of that. Some "pearls" were: [Person \#60, Male, 78] "I try to walk three or four hours a week as exercise", [Person \#67, Male, 70] "When we were children we were always active all the time, which was very good", [Person \#119, Male, 77] "Get out and enjoy life every day. We get out and go for a walk and get a lot of exercise. Do what you like, if you like doing something then do it".

n. 'Not being materialistic, money isn't everything" - The notion that money is important comes as a surprise to no one and because of its central role in every aspect of life it is sometimes necessary to remind ourselves that it is not everything, or even the most important thing. The idea that money cannot buy happiness came through in the responses from the participants: [Person \#32, Male, 82] "Money makes the world go round, but it isn't everything", [Person \#40, Male, 80] "Do what you love doing and don't compromise just so you can make some money", [Person \#76, Male, 79] "Money will buy you a car or a house, but that doesn't make you happy".

o. 'Education and knowledge are important' - Formal education can help vault people forward in their careers, but the importance of everyday, informal learning was also largely valued by our participants. They stressed how learning should never cease as we seek out knowledge in all that we do in our day-to-day lives: [Person \#58, Female, 71] "You have to keep an interest in the other worlds. I read a lot and I used to watch C.N.N. a lot. You have to know what's going on globally", [Person \#62, Female, 84] "I loved learning, and I learned a lot, I loved school", [Person \#80, Male, 71] "I always made sure whatever I did, I learned".

p. 'Immigrating to North America' - Coming to North America and building a new life can be as daunting as it is full of opportunity. Older adults mostly spoke of the apprecia- 
tion they have for their new lives and of the decision they have made to immigrate. Some examples included: [Person \#31, Male, 75] "I'm glad I didn't stay home. Most of my relatives could not even dream of living the kind of life I had here in Canada", [Person \#94, Female, 72] "Moving to Canada from India and attending a senior's club was the best thing that happened to me", [Person \#120, Male, 88] "One of the best decisions I made was coming to Canada".

\section{Discussion}

This study aimed at encouraging life reviews of older adults in hopes of documenting the wisdom they accumulated over their lives'. Through the interviewing process the following themes were all emergent: Adapting and overcoming difficulties, the importance of intergenerational relationships, and achieving satisfaction in life. Following thematic analyses of 132 interviews, the following themes emerged:

\section{Theme 1}

Dealing with Personal Difficulties/Insights on Life and Adapting, was the most populated of all the major themes, touching on a range of concepts associated with individual responsibility, autonomy, and overcoming challenges. Some of the more common ideas included acquiring knowledge and learning from experiences, where the old insight of learning from others' mistakes is always better than learning from your own was communicated. Older adults also highlighted that knowledge is never useless and that travelling to new places or doing something new could provide insight into different ways of doing things. The participants also offered warnings geared to avoid trouble as much as possible, by being cautious, vigilant and doing one's best to avoid or control vices. To this end, they suggested having a goal to guide younger generations, or to avoid bad influences, and that life becomes difficult when people make it difficult on themselves. Further, a premium was placed on a person's unique identity and the ability to express that freely with themes like, be the best you, and see the best in others, I am the captain of my own ship, allowing yourself to be who you are! Because of this, strength of character and resolve were seen as indispensable traits if a person was going to be able to express themselves and succeed in the world. Also related to this, and the most common of all the ideas shared was the importance of determination and hard work, especially when facing adversity. Tied to this concept of determination where phrases and words like, self-reliance, resilience, keep going, fight, don't give up, discipline, persevere, overcoming, just keep trying, drive, stick with it, be strong. Many of these comments were supported by additional advice of taking life seriously, being aware of what the important things in life are and taking an active role of planning your life. And while there was a large focus in the interviews on personal responsibility and self-empowerment, there was also an acknowledgement that not all challenges can be faced alone and that sometimes it is important to seek help when needed, by taking advice, seeking knowledge, learning about life from those who have already lived it, being open to other points of view, and having to shut one's mouth to open one's mind. Other themes mentioned included accepting what cannot be changed, the importance of relationships in the face of loneliness and finding comfort in faith all in relation to overcoming personal difficulties. This connection between resiliency, reminiscence, and older adults has been explored in Meléndez, et la. [29] research which analyzed the effectiveness of a reminiscent program to improve problem-focused coping and resilience in older adults. In a repeated measure study, they showed instrumental reminiscence to be an effective way to improve adaptive capacity and resilience in older adults while providing an improvement in quality of life using the Mini-Mental State Examination, Brief Resilient Coping Scale and Stress Coping Questionnaire. These findings are consistent with our study's goal of not only facilitating the generational exchange of knowledge, but the improvement of well-being in older adults' participants.

\section{Theme 2}

Relationships with Parents and older adults, older adults participating in this theme placed a value of the knowledge and experience they and others possessed which highlights the importance of communication between the generations. This was followed up by encouragement to accept that parents likely have more experience than their children, and how younger people could benefit if they listened more. There were also calls to respect older adults, by being nice, putting down electronics and paying attention, openly expressing love, and helping care for older adults when the needed it. This last idea was elaborated on by comments about how family will care for their own members better than long term facilities, and how they wished they had taken better care of their own parents when they had a chance.

\section{Theme 3}

The final theme encompassed number of concepts including satisfaction of life, making most of the time you have, and appreciating the things you have rather than fixating on the things you still want. Older adults expressed their thoughts by repeating that money is not the end all and be all and how the most cherished things in life are not material in nature. Rather, what did emerge as explicitly vital to the participants were the bond of the family, a person's roots, maintaining health and staying, caring for others, personal freedoms, education and knowledge. Mentions of morality, moderation and balance were also common, with advice given to always be honest, fair and loyal, to avoid drugs and smoking, not looking down on others, and the overarching notion that the universe is just with good things happening to good people. Along with moral concerns, appeals to adopt a positive attitude and taking pride in personal accomplishments were given by the participants as they associated these outlooks with creating a sense of goodwill and optimism in others. Related to this were the themes of living a life full of personal growth, taking opportunities when they presented themselves, time itself being a precious commodity and shorter than you think, and understanding that you need to be responsible for your own happiness. For some participants this advice was related to their own immigration to North America and how such a great life disruption and risk taking shaped their lives in positive ways and gave them a sense of appreciation. As with 
most thematic work, the themes identified here are not completely discreet, as the importance of faith, taking personal responsibility, resilience, being true to yourself, and career success requires work and perseverance all reappeared, but this time, in relation to satisfaction of life.

The relationship between satisfaction of life, reminiscence, and improved outcomes was explored by Viguer, et la. [30] in an experimental study which showed significant improvements in psychological well-being and satisfaction of life where the effects of life satisfaction were still present in a follow up three months afterward. This adds to the evidence that these projects can benefit all parties in meaningful ways and add to a measurable improvement in life quality for older adults.

In concluding, we believe our study has contributed to reminiscence research by highlighting the establishment/ re-establishment of life narratives, preparing for end of life where the reminiscence may be seen as a summary of one's life, and production of life meanings - all of which have been associated with older adults flourishing $[12,14,15]$. We also believe that this study created a resource of guidance and actionable advice focused on navigating life challenges for younger generations, but also enlightening those who care for and work with older adults. Future research may emphasize the production of tangible benefits such as better outcomes for older adults and the preservation and dissemination of knowledge. We would also like to note that this study conducted interviews in the Westernized county of Canada, while we hope that future research could be conducted outside of these communities so that results could be generalized across cultures.

That said, due to previous studies and our own research, we do believe this approach to research to be widely generalizable to many older adult populations, and a net benefit to participants and the wider communities. One more thing that we achieved with this research, is the observation - and in no way was it measured - that it is possible and relatively easy to enhance the connection between youth and the older people, and all we did was use some simple straight forward questions that afford them the opportunity to interact, get to know one another, and exchange ideas.

\section{References}

1. Butler RN (1963) The life review: An interpretation of reminiscence in the aged. Psychiatry 26: 65-76.

2. Erikson EH (1982) The life cycle completed: A review. Norton, New York.

3. Webster JD (2002) Reminiscence functions in adulthood: Age, race, and family dynamics correlates. In: JD Webster, BK Haight, Critical advances in reminiscence work: From theory to application. Springer, New York, USA, P.140-152.

4. Wong $P$, Watt $L(1991)$ What types of reminiscence are associated with successful aging? Psychology and Aging 6: 272-279.

5. Whitbourne, Susan Krauss (1985) The psychological construction of the life-span. In: JE Birren KW Schaie, Handbook of the psychology of aging, Van Nostrand Reinhold, New York, USA, P-594-618.
6. Tomer A, Eliason G (2000) Attitudes about life and death: Toward a comprehensive model of death anxiety. In: A Tomer, Death attitudes and the older adult, Brunner-Routledge, Philadelphia, P. 3-22.

7. Baum SK (1999) Who has no regrets? Psychological Reports 85: 257-260.

8. Cross S, Markus H (1991) Possible selves across the life span. Human Development 34: 230-255.

9. Brinker JK (2013) Rumination and reminiscence in older adults: Implications for clinical practice. European Journal of Ageing 10: 223-227.

10. Cappeliez P, O'Rourke N (2006) Empirical validation of a model of reminiscence and health in later life. J Gerontol B Psychol Sci Soc Sci 61: 237-244.

11. Giddens A (1991) Modernity and self-identity. Polity Press, Cambridge, UK.

12. Bohlmeijer E, Roemer E, Cuijpers $P$, et al. (2007) The effects of reminiscence on psychological well-being in older adults: A meta-analysis. Aging Mental Health 11: 291-300.

13. Chin AMH (2007) Clinical effects of reminiscence therapy in older adults: A meta-analysis of controlled trials. Hong Kong Journal of Occupational Therapy 17: 10-22.

14. Chiang KJ, Lu RB, Chu H, et al. (2008) Evaluation of the effect of a life review group program on self-esteem and life satisfaction in the elderly. Int J Geriatr Psychiatry 23: 7-10.

15. Stinson CK (2009) Structured group reminiscence: An intervention for older adults. J Contin Educ Nurs 40: 521-528.

16. Lin YC, Dai YT, Hwang SL (2003) The effect of reminiscence on the elderly population: A systematic review. Public Health Nursing, 20: 297-306.

17. Lin CJ, Liu SJ, Chen YM, et al. (2007) The effects of group reminiscence therapy on self esteem, depression, loneliness and life satisfaction of elderly people living alone. Mid-Taiwan Journal of Medicine 12: 133-142.

18. Pinquart M, Forstmeier S (2012) Effects of reminiscence interventions on psychosocial outcomes: A meta-analysis. Aging \& Mental Health 16: 541-558.

19. Chao SY, Liu HY, Wu CY, et al J. (2006). The effects of group reminiscence therapy on depression, self esteem, and life satisfaction of elderly nursing home residents. J Nurs Res 14: 36-45.

20. Coleman $P$ (1994) Reminiscence within the study of ageing. In: J Bornat ( $1^{\text {st }}$ edn), Reminiscence reviewed: Perspectives, evaluations, achievements, Open University Press, Buckingham, UK, P. 8-20.

21. Chung JCC (2009) An intergenerational reminiscence programme for older adults with early dementia and youth volunteers: Values and challenges. Scand J Caring Sci 23: 259-264.

22. Webster JD, McCall ME (1999) Reminiscence functions across adulthood: A replication and extension. Journal of Adult Development 6: 73-85.

23. Abrams D, Crisp RJ, Marques S, et al. (2008) Threat inoculation: Experienced and imagined intergenerational contact prevents stereotype threat effects on older people's math performance. Psychol Aging 23: 934-939.

24. Abrams D, Eller A, Bryant J (2006) An age apart: The effects of intergenerational contact and stereotype threat on performance 
and intergroup bias. Psychology and Aging, 21: 691-702.

25. Bohlmeijer E, Valenkamp M, Westerhof G, et al. (2005) Creative reminiscence as an early intervention for depression: Results of a pilot project. Aging Ment Health 9: 302-304.

26. Scott K, DeBrew JK (2009) Helping older adults find meaning and purpose through storytelling. J Gerontol Nurs 35: 38-43.

27. Heinz M, Cone N, da Rosa G, et al. (2017) Examining supportive evidence for psychosocial theories of aging within the oral history narratives of centenarians. Societies 7: 8 .
28. Braun V, Clarke V (2006) Using thematic analysis in psychology. Qualitative Research in Psychology 3: 77-101.

29. Meléndez Juan C, Flor B Fortuna, Alicia Saleset, et al. (2015) The effects of instrumental reminiscence on resilience and coping in elderly. Archives of Gerontology and Geriatrics 60: 294-298.

30. Viguer Paz, Encarna Satorres, Flor B Fortuna, et al. (2017) A follow-up study of a reminiscence intervention and its effects on depressed mood, life satisfaction, and well-being in the elderly. The Journal of Psychology 151: 789-803. 